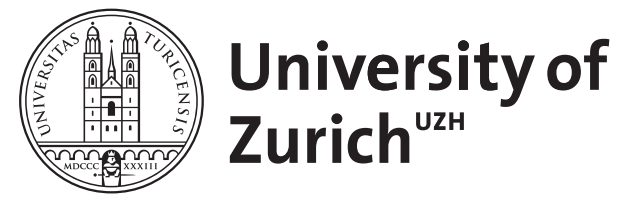
Archive

University of Zurich

University Library

Strickhofstrasse 39

CH-8057 Zurich

www.zora.uzh.ch

Year: 2012

\title{
The chorea of McLeod syndrome: Progression to hypokinesia
}

Miranda, M ; Jung, H H ; Danek, A ; Walker, R H

DOI: https://doi.org/10.1002/mds.25224

Posted at the Zurich Open Repository and Archive, University of Zurich

ZORA URL: https://doi.org/10.5167/uzh-67671

Journal Article

Accepted Version

Originally published at:

Miranda, M; Jung, H H; Danek, A; Walker, R H (2012). The chorea of McLeod syndrome: Progression to hypokinesia. Movement Disorders, 27(13):1701-1702.

DOI: https://doi.org/10.1002/mds.25224 
Video is part of Ms

\title{
Clinical Vignette
}

\section{The chorea of McLeod syndrome: progression to hypokinesia}

Marcelo Miranda ${ }^{1}$, Hans H. Jung ${ }^{2}$, Adrian Danek ${ }^{3}$, Ruth H. Walker ${ }^{4}$

\author{
${ }^{1}$ Department of Neurology, Clinica Las Condes, Santiago, Chile; \\ ${ }^{2}$ Department of Neurology, University Hospital Zurich, Switzerland; \\ ${ }^{3}$ Neurologische Klinik, Ludwig-Maximilians-Universität, München, Germany; \\ ${ }^{4}$ Department of Neurology, Veterans Affairs Medical Center, Bronx, NY, USA
}

\begin{abstract}
${ }^{4}$ To whom correspondence should be addressed:
Ruth H. Walker, M.B., Ch.B., Ph.D.,

Department of Neurology (127),

130 W. Kingsbridge Road

James J. Peters Veterans Affairs Medical Center,

Bronx, NY 10468
\end{abstract}

Tel: 718-584-9000 x5915

Fax: 718-741-4708

email: ruth.walker@mssm.edu 


\section{Introduction}

Before the identification of McLeod neuroacanthocytosis syndrome (MLS) and choreaacanthocytosis ( $\mathrm{ChAc}$ ) as genetically distinct disorders, these two disorders, which have remarkable clinical similarities, were confusinglylumped together under the term “neuroacanthocytosis.' Genetic diagnosis has enabled us to identify features that initially appeared to be specific to each of the disorders. However, with increased availability of genetic and proteinbased testing, it has become apparent that certain phenotypic features thought to be specific to one disorder may indeed be found in the other, such as feeding dystonia ${ }^{1}$ and head drops. ${ }^{2}$ Here we provide video documentation of a case of MLS that evolved from chorea to parkinsonism, a disease course that has not previously been reported on, and that is more typical of ChAc. ${ }^{3}$

MLS is an X-linked disorder with central nervous system (CNS) features similar to Huntington's disease (HD). ${ }^{3,4}$ MLS is caused by mutations in the XK gene encoding for the XK protein, which presents the Kx blood-group antigen on red blood cells (RBCs). ${ }^{3-5}$ The CNS manifestations of MLS usuallystart in the fourth or fifth decades and comprise chorea, psychiatric symptoms, cognitive decline, and tonic-clonic seizures. ${ }^{3-5}$ Neuromuscular manifestations include axonal sensorimotor neuropathy, neurogenic muscle atrophy, and myopathy. ${ }^{3-5}$ Hepatosplenomegaly and cardiomyopathy are typical. ${ }^{3-5}$ Diagnosis of MLS is indicated by the HD-like features, additional neuromuscular manifestations, in particular, absent or diminished deep tendon reflexes, and the laboratory findings of elevated creatine kinase (CK) levels, RBC acanthocytosis, and the presence of the McLeod blood-group phenotype. Neuroradiological studies demonstrate progressive striatal atrophy.

\section{Case report}

The patient was a chemical engineer, the elder of two brothers affected with MLS, as previously described. ${ }^{6}$ He presented at age 56 and reported a 9-year history of a chorea associated with episodic major depression. He noted reduced ability to concentrate at work and diminished ability to control his emotions in everyday life. In addition, he showed obsessive-compulsive symptoms, such as checking and ordering in symmetry and exactness. Upon first neurological examination, he was alert and fully oriented. Cognitive testing demonstrated a mild impairment. He had generalized chorea, tic-like grimacing, shoulder shrugging, and sniffing (see Video, Segment 1, 2 years after presentation). Blood examination after dilution with heparinized isotonic 
saline demonstrated 29\% acanthocytes. Cerebral MRI showed marked caudate atrophy. Molecular genetic analysis of the XK gene demonstrated a 5-bp (base-pair) deletion in exon 2 of the XK gene (c. 938-942delCTCTA). ${ }^{6}$

After 8 years, he developed marked progressive parkinsonian features with a masked facies and reduced blinking, frontalis contraction similar to that observed in progressive supranuclear palsy, hypophonic and monotonous speech, rigidity, and generalized bradykinesia (see Video, Segment 2). The patient is wheelchair bound as the result of myopathy. ${ }^{7}$ He had not received dopamine (DA) D2-receptor blocking drugs. Parkinsonian symptoms responded only partially to levodopa in doses up to $1 \mathrm{~g}$ daily. $99 \mathrm{mTc}$-TRODAT- 1 single-photon emisi $\square$ on computed tomography (SPECT) scan showed a marked decrease in putamen DA transporter binding, consistent with loss of nigrostriatal neurons (Fig. 1).

\section{Discussion}

Both MLS and ChAc may present with a variety of movement disorders in the same patient during the course of the disease. Hyperkinetic features may be attributed to loss of striatal projection neurons, presumably enkephalinergic neurons, which comprise the indirect pathway, as in early HD. ${ }^{8}$ Akinetic-rigid features may be the result of striatonigral degeneration, with loss of striatal projection neurons of the direct pathway, comparable to advanced $\mathrm{HD}$, and, as suggested in this case, by a minimal response to Ldopa. As demonstrated by the SPECT data, loss of nigrostriatal dopaminergic neurons may also play a role. The neuropathology of MLS typically involves, predominantly, the caudate nucleus and putamen, but not the $\mathrm{SN} .{ }^{9}$ It is more common for patients with ChAc to show a progression from a hyperkinetic syndrome with chorea and tics to parkinsonism and dystonia. Correspondingly, the neuropathology of ChAc is more extensive, ${ }^{10}$ involving the $\mathrm{SN}$, globus pallidus, and thalamus, in addition to primarily affecting the caudate nucleus and putamen. Thus, even though, with genetic advances, MLS and ChAc have diverged from being covered by the umbrella term of neuroacanthocytosis, it may be that they are ultimately more similar and, possibly, may share a common underlying pathophysiology, with MLS being the result of the same process at the cellular level as ChAc, but with later onset. 
Legends to the video

Segment 1. The patient presented with generalized chorea, shoulder shrugging, and sniffing. Segment 2. The patient now has a masked facies with reduced blinking, hypophonic and monotonous speech, and generalized bradykinesia.

\section{Figure 1}

99mTc-TRODAT-1 SPECT. The Mc Leod patient (A and B) shows marked loss of putaminal dopamine transporter binding in comparison to a normal subject $(\mathrm{C})$.
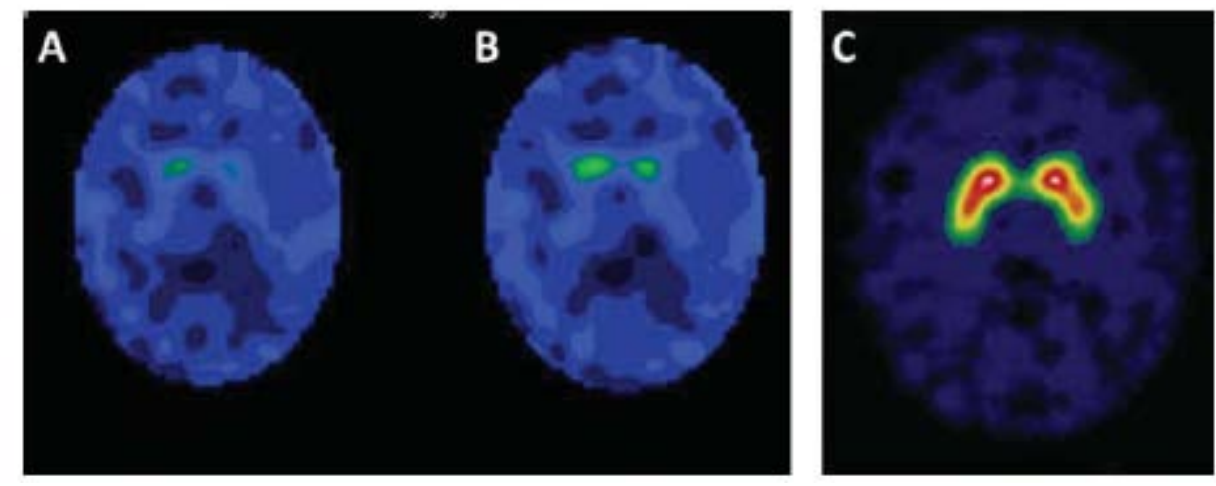

\section{References}

1. Gantenbein AR, Damon-Perriere N, Bohlender JE, et al. Feeding dystonia in McLeod syndrome. Mov Disord 2011;26: 2123-2126.

2. Chauveau M, Damon-Perriere N, Latxague C, et al. Head drops are also observed in McLeod syndrome. Mov Disord 2011;26: 1562-1563.

3. Danek A, Rubio JP, Rampoldi L, et al. McLeod neuroacanthocytosis: genotype and phenotype. Ann Neurol 2001;50:755-764.

4. Jung HH, Danek A, Walker RH, Frey BM, Gassner C. McLeod neuroacanthocytosis syndrome. In: Pagon RA, Bird TD, Dolan CR, Stephens K, Adam MP, eds.

GeneReviews at GeneTests [online]. Seattle, WA: University of Washington Seattle; updated 2012 May 17.

5. Symmans WA, Shepherd CS, Marsh WL, Oyen R, Shohet SB, Linehan BJ. Hereditary acanthocytosis associated with the McLeod phenotype of the Kell blood group system. Br J Haematol 1979; 42:575-583.

6. Miranda M, Castiglioni C, Frey BM, Hergersberg M, Danek A, Jung HH. Phenotypic variability of a distinct deletion in McLeod syndrome. Mov Disord 2007;22:1358-1361.

7. Hewer E, Danek A, Schoser BG, et al. McLeod myopathy revisited: more neurogenic and less benign. Brain 2007;130:3285-3296. 
8. Albin RL, Reiner A, Anderson KD, et al. Preferential loss of striato-external pallidal projection neurons in presymptomatic Huntington's disease. Ann Neurol 1992;31:425430.

9. Geser F, Tolnay M, Jung HH. The neuropathology of McLeod syndrome. In: Walker RH, Saiki S, Danek A, eds. Neuroacanthocytosis Syndromes II. Berlin: SpringerVerlag; 2008:197-203.

10. Bader B, Arzberger T, Heinsen H, Dobson-Stone C, Kretzschmar HA, Danek A. Neuropathology of chorea-acanthocytosis. In: Walker RH, Saiki S, Danek A. eds. 